\title{
Major depression in Parkinson's disease and the mood response to intravenous methylphenidate: possible role of the "hedonic" dopamine synapse
}

\author{
R CANTEllo,* M AGUGgiA, M GILli, M DELSEDIME, I CHIARDò CUTIN, \\ A RICCIO, R MUTANI*
}

From the Department of Neurology, University School of Medicine, Turin, and Novara, ${ }^{*}$ Italy

SUMMARY The euphoric response to equivalent doses of intravenous methylphenidate (MTP) was assessed in a group of 13 Parkinsonian patients affected by major depression, in a group of 11 nondepressed Parkinsonians, in a group of 14 nonparkinsonian subjects suffering from major depression, and finally in a group of 12 controls with no CNS or psychiatric disease. Subjects of al four groups were matched for age, sex and other main characteristics. Depressed and nondepressed Parkinsonians were also matched for duration and severity of illness, and for the type of antiparkinsonian treatment. The response to MTP was evaluated in the context of a double-blind, placebo-controlled study. Parkinsonian patients with major depression exhibited a significant lack of sensitivity to the euphoriant effects of MTP, in comparison with the other three groups. Euphoria produced by central stimulants has been shown to depend on the activity of a dopamine synapse in humans, which is thought to be situated at the limbic terminals of dopamine neurons located in the ventral tegmental area. Degeneration of this system may have predisposed our Parkinsonian patients to major depression.

Many investigators have been intrigued by the possibility that there are specific aetiological mechanisms of depression in Parkinson's disease. Gotham et al have discussed the inconsistencies of most of their results. Since Parkinsonians suffer from a chronic disability, they are unquestionably prone to "reactive" depression. However, most authors, ${ }^{2-5}$ though not Horn $^{6}$ and Gotham et al reached the conclusion that adverse mood changes are more frequent among Parkinsonians than among other, equally disabled, patients. This, and the fact that depression often antedates the cardinal features of Parkinson's disease ${ }^{7-}$ ${ }^{10}$ cannot be immediately reconciled with a merely reactive aetiology. If the depression were purely reactive, a direct correlation between disease duration or severity and degree of depression should be found. Warburton, ${ }^{2}$ Celesia and Wanamaker, ${ }^{7}$ Marsh and Markham $^{3}$ and Mayeux et $a l^{9}$ found none and Mayeux et $a l,{ }^{8}$ as well as Gotham et al, ${ }^{\prime}$ found only a

Address for reprint requests: $\mathrm{R}$ Cantello $\mathrm{MD}, \mathrm{PhD}$ (Rome). Via Foscolo 6, 10126 Torino, Italy.

Received 5 January 1988 and in revised form 10 October 1988. Accepted 17 October 1988 weak correlation. Thus other factors, including personal and social features, must contribute to Parkinson's disease depression. ${ }^{1}$ Several authors ${ }^{45911}$ have wondered whether some pathological features of the Parkinsonian brain may interact with reactive determinants in the emergence of depression. Post-mortem studies $^{12}$ have shown that the metabolism of many transmitters and modulators classically implicated ${ }^{13}$ in affective behaviour is deranged in Parkinson's disease. Moreover, there is growing evidence that depressed Parkinsonians may have a decreased cerebrospinal fluid 5-hydroxyindoleacetic acid level ${ }^{1415}$ which is thought to indicate impairment of the central serotonin metabolism. It may be remembered that Fibiger ${ }^{16}$ focused on the hypothesis that Parkinson's disease depression might correlate with anatomofunctional derangement of the dopaminergic fibres that arise from the ventral tegmental area (VTA) of the mesencephalon, and are usually referred to simplistically as the "mesolimbic dopamine system". One of their most characteristic features is their crucial importance in the reward effect produced by amphetamine self-administration or other procedures in various animal species. ${ }^{16}$ In humans too dopamine circuitry 
has been shown to be essential to the production of stimulant-mediated euphoria. ${ }^{17-19}$

In a recent study of mood fluctuations associated with "end-of-dose deterioration" in Parkinson's disease, ${ }^{5}$ we concluded that central dopaminergic deficiency, possibly at non-nigrostriatal sites, very probably played a predisposing or contributory role in our patients' depression. Discussing their experiments on short-term memory in depressed patients with Parkinson's disease, Taylor et al ${ }^{\prime \prime}$ concluded that deranged dopaminergic innervation of the prefrontal cortex may have predisposed their subjects to the depressive features that emerged during testing.

These considerations combined to provide us with our working hypothesis: if, in a given Parkinsonian patient, major depressive mood changes are somehow related to impaired function of VTA-derived dopamine fibres, his response to the euphoriant effect of a standard dose of a central stimulant may be expected to be diminished or suppressed. Depression per se may alter the mood response to central sympathomimetics, ${ }^{20}$ which anyway shows some variability in the normal population. ${ }^{21}$ We assessed behavioural changes associated with the intravenous injection of an amphetamine-like compound, namely methylphenidate, in a group of Parkinsonian patients with major depression in the context of a double-blind and placebo-controlled study. We then contrasted the results with those obtained in a group of Parkinsonian subjects without depression, in a group of nonparkinsonian subjects suffering from major depression and finally in a group of controls without CNS or psychiatric disease.

\section{Subjects and methods}

Parkinson's disease patients Twenty-four patients with idiopathic Parkinson's disease attending the Parkinson's disease Centre of our Institute were selected for the study: 14 males and 10 females, aged from 40 to 65 years $($ mean $=56 \cdot 1 ; \mathrm{SD}=7 \cdot 3)$.

Criteria for selection were: (a) absence of signs or symp- toms of ischemic brain damage on neurological examination and CT of the head; (b) Hachinski Ischemic Score ${ }^{22}$ below 4 and Mini-mental state ${ }^{23}$ score above 24 ; (c) no family history of endogenous (major) depression; (d) absence of sudden motor fluctuations; (e) duration of illness ranging from 1 to 5 years; (f) presence of moderate-to-severe akinetic symptoms on the Columbia University Rating Scale (CURS). ${ }^{24}$ The last two criteria were adopted to ensure a comparable degree of nigro-striatal dopamine loss. ${ }^{24}$ Of the 24 Parkinson's disease patients, 13 were selected for the presence of major depression, according to DSM III criteria. ${ }^{26}$ Depression in the Parkinson's disease as well in the other groups was also evaluated by means of the Beck Depression Inventory, the use of which in the assessment of these patients has now been widely and authoritatively accepted. ${ }^{1810112829}$ As in previous studies, ${ }^{530}$ we used a shortened form of this scale, which omitted some items unduly affected by Parkinsonian motor features (sBDI). Depressed Parkinsonians were also assessed for the "anhedonic" presentation of their depression by means of the method described by Fawcett et al. ${ }^{31}$ Patients with motor fluctuations due to long-term levodopa treatment were assessed on the psychiatric and Parkinsonian scales during their "on" period. On the DSM III and sBDI criteria, 11 Parkinsonians were in turn classified as free from depression. The main characteristics of depressed and nondepressed patients with Parkinson's disease are summarised in table 1. There was no significant difference in the overall disease severity or duration between the two groups. Parkinsonian patients were receiving antiparkinsonian drugs, which were withdrawn at least 72 hours before the experiment described below. The duration of antiparkinsonian treatment was similar in the two groups, as was the type of medication. Some patients were also taking antidepressants, but these were stopped one month prior to this study.

Patients with major depression Fourteen subjects with major depression according to DSM III criteria ${ }^{26}$ were selected from those referred for admission to a private psychiatric nursing and rehabilitation centre. Criteria of exclusion were: (a) abnormalities on physical or neurological examination; (b) Hachinski Ischemic Score ${ }^{22}$ above 4 and Mini-mental state ${ }^{23}$ score below 24; (c) signs of organic brain damage on CT of the head; (d) history of sympathomimetic abuse. These patients were matched with the Parkinsonian group for age, sex, duration of illness and years of education (table 1). Like depressed Parkinsonians, they were also assessed on the Fawcett and Clark Pleasure Scale ${ }^{31}$ for the

Table 1 Some characteristics of patients and controls

\begin{tabular}{|c|c|c|c|c|c|c|c|c|c|}
\hline & \multirow[b]{2}{*}{$\begin{array}{l}\text { Mean age } \\
(y r)(S D)\end{array}$} & \multicolumn{2}{|c|}{ Sex } & \multirow{2}{*}{$\begin{array}{l}S B D I \\
(S D)\end{array}$} & \multirow{2}{*}{$\begin{array}{l}\text { Anhedonic* } \\
\text { patients (\%) }\end{array}$} & \multirow[b]{2}{*}{ CURS } & \multirow[b]{2}{*}{$\begin{array}{l}\text { Duration of } \\
\text { illness }(S D)\end{array}$} & \multirow[b]{2}{*}{$\begin{array}{l}\text { Education } \\
(y r(S D))\end{array}$} & \multirow{2}{*}{$\begin{array}{l}\text { Minimental } \\
\text { state }\end{array}$} \\
\hline & & $F$ & $M$ & & & & & & \\
\hline $\begin{array}{l}\text { Depressed Parkinsonians } \\
(\mathrm{n}=13) \\
\text { Nondepressed }\end{array}$ & $57 \cdot 1(6 \cdot 4)$ & 6 & 7 & $28 \cdot 2(5 \cdot 9)$ & 77 & $34 \cdot 7(12)$ & $4 \cdot 1(1 \cdot 2)$ & $10 \cdot 1(4 \cdot 9)$ & $27 \cdot 9(2 \cdot 1)$ \\
\hline $\begin{array}{l}\text { Parkinsonians } \\
(\mathrm{n}=11)\end{array}$ & $55.9(7.0)$ & 4 & 7 & $4 \cdot 3(1 \cdot 9)$ & - & $33 \cdot 3(11)$ & $4 \cdot 5(1 \cdot 5)$ & $12 \cdot 8(6 \cdot 2)$ & $27 \cdot 2(2 \cdot 3)$ \\
\hline $\begin{array}{l}\text { Patients with major } \\
\text { depression }(n=14) \\
\text { Controls }(n=12)\end{array}$ & $\begin{array}{l}59 \cdot 0(5 \cdot 6) \\
61 \cdot 2(8 \cdot 1)\end{array}$ & $\begin{array}{l}6 \\
5\end{array}$ & $\begin{array}{l}8 \\
7\end{array}$ & $\begin{array}{r}25 \cdot 7(6 \cdot 3) \\
3 \cdot 3(1 \cdot 8)\end{array}$ & $28 \cdot 5$ & - & $\begin{array}{l}5.9(3.7) \\
6.0(2.6)\end{array}$ & $\begin{array}{l}13.7(6.8) \\
13.1(7.0)\end{array}$ & $\begin{array}{l}28.1(2.1) \\
28.6(2.9)\end{array}$ \\
\hline
\end{tabular}

sBDI: score on the shortened form of the Beck Depression Inventory ${ }^{27}$ (mean value (SD)).

CURS: score on the Columbia University Rating Scale ${ }^{24}$ (mean value (SD)).

Minimental state: score on the Minimental state ${ }^{33}$ (mean value (SD)).

*As assessed by the method proposed by Fawcett and Clark ${ }^{31}$. 
anhedonic component of their depression. Since they were referred because of a very recent recurrence of their depressive symptoms, most of these patients were not being given a standard antidepressive treatment. Two of them were receiving 75-100 mg of clomipramine, and four were taking lithium salts. These drugs were discontinued at least two weeks before the experimental procedure.

Controls Twelve subjects, matched for age, sex and years of education with the previous two groups (table 1), were selected from those routinely admitted to our department for lumbar disk pathology $(n=10)$ or cervical spondylosis $(n=2)$. Criteria of exclusion were: (a) family or personal history of major depression; (b) history of alcohol or drug abuse; (c) Hachinski Ischemic Score ${ }^{22}$ above 4 and Minimental state ${ }^{23}$ score below 24; (d) signs of organic brain damage on CT of the head. As usual, they were studied by means of the sBDI and the DSM III criteria. None of these subjects was being treated with psychotropic drugs.

Methylphenidate trial As injectable amphetamine preparations are not available in our country for human use, we carried out our behavioural study with methylphenidate (MTP). The pharmacological properties of this drug are very subtly different from those of amphetamines, ${ }^{32}$ but MTP undoubtedly produces euphoriant effects, which are far more evident when the intravenous route is used, and are selectively suppressed by dopamine receptor blockers. ${ }^{18}$ The subjects of all four groups were admitted to our department, where cardiological examination and ECG were done. Subjects at risk for arrhythmias or other cardiovascular disease were excluded. Participants were told they would be given a drug that "in many of them would produce mood amelioration and increased activity". Experimental methods and possible (though unlikely) hazards were also explained. After consent was obtained, all the subjects received, according to a randomised sequence, an intravenous injection of either methylphenidate $(0.4 \mathrm{mg} / \mathrm{kg})$ or placebo (saline) in a double-blind, single-crossover trial. The two infusions were separated by at least three days, and were performed fairly slowly ( $3 \mathrm{~min}$ ). MTP was diluted in $20-\mathrm{ml}$ saline. Arterial blood pressure and heart rate were monitored throughout the experiments. During the 2 hours following injections, changes in the psychic status were evaluated by means of an Italian translation of a self-rating scale which was validated by Van Kammen and Murphy ${ }^{17}$ to measure amphetamine responses over a $0-5$ point range (Appendix). This scale included items covering psychic activation, euphoria, depressed effect, dysphoria and somatic side effects. Patients and controls, lying comfortably in a quiet room, were asked to complete the scale at time 0 (that is before injections) and then $5,15,30,60$ and 120 minutes later, while the same "blind" neurologist (RC) observed their behaviour. Subjects were allowed to ask the observer for any explanations about the scale items or other details of the experiment. At the end of each session, the observer provided a global judgment of the patients' behavioural changes, according to the method proposed by Wald et $a l^{18}$; marked pressure of speech and verbalised feelings of euphoria and obvious physical hyperactivity were rated 4 points; moderate pressure of speech, verbalised euphoria and some increased motor activity were rated 3 points; moderate pressure of speech, some positive affective changes and increase in sexual and/or aggressive speech contents were rated 2 points; mild increase in flow of speech was rated 1 point. Finally, no changes or adverse changes were rated 0 .

Effects of methylphenidate on Parkinsonian symptoms Since MTP has been reported to influence some of the cardinal features of Parkinson's disease, ${ }^{33}$ depressed and nondepressed Parkinsonian patients were also rated on the CURS ${ }^{24}$ by the "blind" observer before the injection of either methylphenidate or placebo, as well as 20 and 60 minutes later.

Data analysis After preliminary analysis avoided contamination and to simplify data handling, scores obtained on the "euphoria" and the "activation" items were summed up for each subject and each experimental session. An "activation plus euphoria" (AE) total score was thus calculated for time 0 (baseline assessment) and subsequent times of selfrating. In the same way, a "depressed affect plus dysphoria" (DD) and a "somatic symptoms" (SS) total score were obtained. The mean values for the AE, DD and SS total scores throughout both the MTP and the placebo experiments were then calculated in each of the four groups. The significance of the mean differences between baseline values and subsequent ones in the same trial was evaluated by means of a two-tailed Wilcoxon Signed Rank test. This was also used to test the significance of the mean within-group differences in the AE, DD and SS total scores between the methylphenidate and the placebo experiment. The (methylphenidate-placebo) mean difference in the total scores in each of the four groups was then contrasted with that of the remaining three by means of a two-tailed Wilcoxon Rank Sum test.

In each of the four groups and for both the MTP and the placebo sessions, the mean values of the observer's global judgement score were also calculated, and the significance of their difference was evaluated by means of a two-tailed Wilcoxon Signed Rank test. The (MTP-placebo) mean difference in the observer's score in each of the four groups was then contrasted with that of the remaining three by means of a two-tailed Wilcoxon Rank Sum test.

A direct inter-group comparison for the variables mentioned above and their differences was subsequently performed by means of repeated measures analysis of variance.

Individuals were rated "positive responders" to an injection if they showed an increase in their AE total score and/or a decrease in their DD total score by at least $100 \%$ throughout the experiments. The proportion of positive responders in the four groups were compared by means of a chi-square test.

Within-group correlations and the test-retest reliability of the self-rating scale adopted in the two sessions were calculated by means of a two-tailed Spearman Rank correlation test.

\section{Results}

Mood response to methylphenidate The test-retest reliability (Spearman Rank Correlation test) of the self-rating scale used in the methylphenidate and the placebo sessions, with reference to the baseline assessment, was 0.86 in the nondepressed Parkinsonian group, 0.83 in the depressed Parkinsonians, 0.79 in the group of patients with major depression and 0.78 in controls. Since analysis of the changes in the somatic 
symptoms elicited nothing of interest in any of the four groups, this topic will not be discussed further.

The figure (A) shows the mean changes in the "activation plus euphoria" (AE) and "depressed affect plus dysphoria" (DD) total scores in the nondepressed Parkinsonian group following methylphenidate and placebo injections. On average, these patients showed a clear and significant mood amelioration in response to the active drug, but not to placebo. The response began within 5 minutes of MTP injection, and reached its peak 15 to 30 minues later, tending to disappear within two hours.

The baseline DD total score was clearly higher in the depressed Parkinsonians than in the previous group, whereas the AE total score was markedly lower (fig, B). Depressive feelings in this group showed a very slight tendency to decrease after the methylphenidate injection, though not significantly, even in comparison with placebo effects. Conversely, the initially low AE total score was not significantly elevated (fig, B).
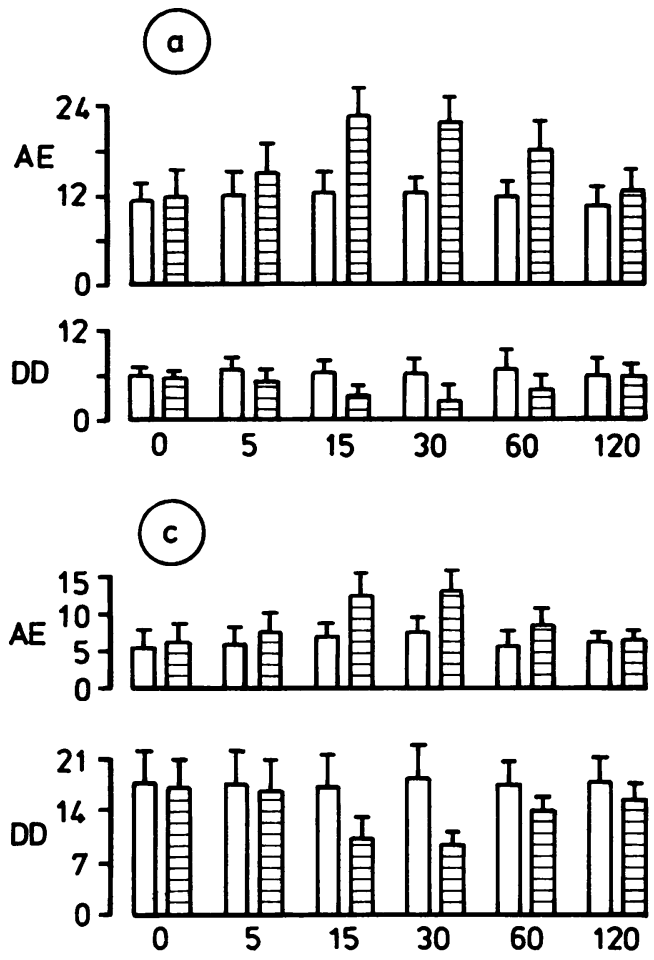
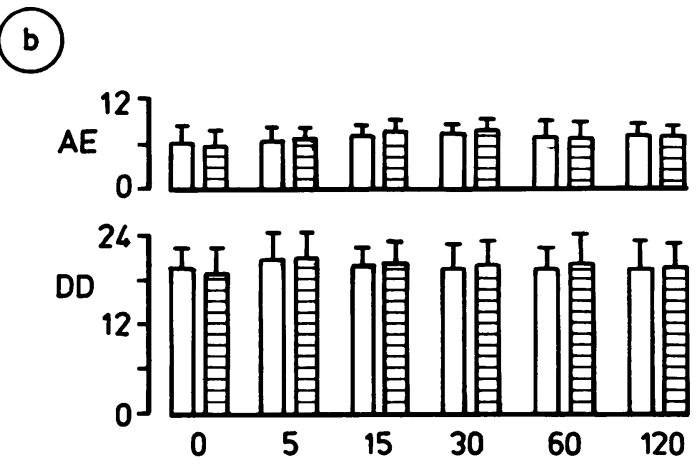

(d)
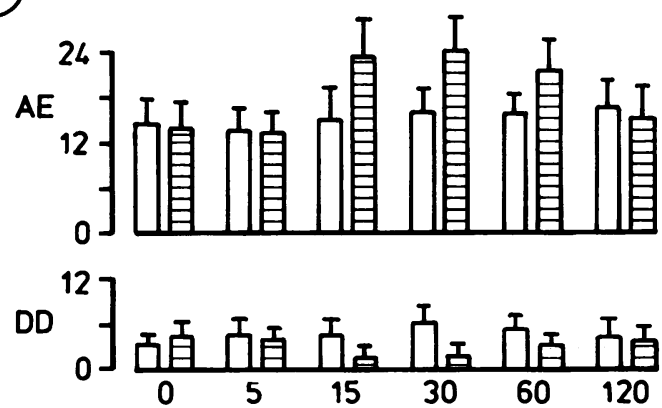

Fig Average changes of the psychic status, assessed by means of the self-rating scale reported in the Appendix, in the four groups throughout the methylphenidate (striped columns) and the placebo (white columns) experiments. (A) Non depressed Parkinsonians. There is a clear response to the intravenous injection of methylphenidate (MTP), expressed by decrease of the $D D$ and increase of the AE indexes. For the DD total score, the MTP-associated change is statistically significant ( $p<0.01$, Wilcoxon Signed Rank test) both in comparison with baseline and with placebo values 15, 30 and 60 minutes after the injection. For the AE total score, the change is already significant $(p<0.05) 5$ minutes after the injection, while it becomes more significant $(p<0.01)$ subsequently $(15,30$ and 60 minutes after the injection). (B) Parkinsonian patients with major depression. No significant change is detected in the DD or in the E total score throughout the MTP experiment, both in comparison with baseline and with placebo values. (C) Patients with major depression but without Parkinson's disease. A significant ( $p<0 \cdot 01$, Wilcoxon Signed Rank test) decrease in the DD total score and a parallel increase in the AE total score $(p<0.01$, Wilcoxon Signed Rank test) is detected 15 and 30 minutes after the injection of methylphenidate, both in comparison with baseline and with placebo values. For both indexes, the change is still significant $(p<0.05) 60$ minutes after the injection. (D) Control group. A paradoxical increase in the DD total score is detected 30 minutes after the injection of placebo ( $p<0.05)$. The DD and the AE total scores show significant specular changes $(p<0.01$, Wilcoxon Signed Rank test) both in comparison with baseline and with placebo values 15 and 30 minutes after the methylphenidate injection. The change is still significant 60 minutes after the injection, though to a lesser degree $(p<0 \cdot 05$, Wilcoxon Signed Rank test $)$. $x$ axis: time expressed as minutes; $y$ axis: mean depression plus dysphoria (DD) and activation plus euphoria (AE) total scores on the self-rating scale, obtained as explained in the text. Note: analysis of variance studies confirmed the levels of significance reported above. 
Patients with major depression but without Parkinson's disease (fig, C) had baseline AE and DD total scores similar to depressed Parkinsonians. As a group, they showed significant relief of depressive symptoms when given methylphenidate but not placebo. This emerges from the clear decrease in the DD total score and from the detectable increase in the AE score. The time course of the response resembled that of nondepressed Parkinsonians.

The control group (fig, 4) likewise presented significant euphoria and activation in response to methylphenidate, expressed by decrease of the DD and increase of the AE total scores. Placebo had no significant effect. The time course of the drug effect was again similar to that of nondepressed Parkinsonians.

An inter-group comparison shows that the absolute (methylphenidate-placebo) difference in the DD and the AE total scores was lower in the depressed PD group than in the other three $15(p<0.01), 30$ $(p<0.001)$ and $60(p<0.005)$ minutes after the MTP injection.

As far as the observer's global judgment score is concerned (table 2), the mean (methylphenidateplacebo) difference in the nondepressed parkinsonian and in the control group is significant $(p<0.01)$. It is also significant, though to a lesser degree, in the group of patients with major depression but without Parkinson's disease $(p<0.05)$, whereas this is not the case for depressed Parkinsonians. In an inter-group comparison, the (methylphenidate-placebo) mean difference in the depressed Parkinsonian group is significantly lower than in any other group $(p<0.05)$.

The percentage of positive responders (as previously defined) to methylphenidate injections was $73 \%$ in the nondepressed Parkinsonians, $15 \%$ in the depressed Parkinsonians, $50 \%$ in the nonparkinsonian depressed group and $67 \%$ in controls. On analysis, a chisquare value of $9.92(p<0.05)$ is obtained, the main contribution to which (5.54) comes from the depressed Parkinsonian group. The distribution of positive responders thus differs significantly in the four groups, owing to the exceedingly low proportion found among depressed Parkinsonians.

Detailed correlation studies were carried out in each of the four groups for the main variables.
The only significant correlation $(r=+0.68$; $p<0.01$ ) was a positive one, which was calculated between the sBDI score and the DD total score 30 minutes after the injection of methylphenidate in the depressed Parkinsonian group. We shall therefore not tabulate the rest of the data.

Effects of methylphenidate on Parkinsonian symptoms Methylphenidate was found to influence Parkinsonian motor signs in a variable fashion: 15 individuals obtained good relief of rigidity and akinesia (by $50 \%$ or more on their CURS score), while the remaining nine did not. Improvement was found in seven of 11 of the nondepressed and in eight of 13 of the depressed Parkinsonian patients. Tremor showed a uniform tendency to a reversible worsening. We also observed that patients suffering from primary sensory symptoms unexpectedly benefited from the administration of methylphenidate, and this will be reported elsewhere. ${ }^{34}$

The two depressed patients who were classified as "positive responders" to methylphenidate experienced a striking global improvement of motor disability, which was quite severe because of levodopa withdrawal (see Methods). Some 15 minutes after the MTP injection they were able to rise promptly from their bed, walk around in the ward corridor and speak in a very clearly intelligible voice. This was preceded and accompanied by a very pronounced mood amelioration, with intense feelings of euphoria and a tendency to hyperactivity. Both subjects spontaneously reported the drug had reproduced that total reversal of disability they sometimes experienced when influenced by specific (pleasurable) emotional situations. This phenomenon resembled "kinesia paradoxica", recognised by Marsden and Parkes, ${ }^{35}$ and was never experienced by any of the remaining 22 Parkinsonian patients.

\section{Discussion}

The intravenous injection of small-to-medium doses of central sympathomimetics, such as methylphenidate, is followed in most normal subjects by a charcteristic syndrome: feelings of euphoria and wellbeing, psychic activation, talkativeness and a general increase in locomotor activity. ${ }^{21}$ Such effects can be

Table 2 Observer's global judgment score.* (0-4 scale; mean value (SD)

\begin{tabular}{llll}
\hline & Methylphenidate & Placebo & Difference \\
\hline Depressed Parkinsonians $(\mathrm{n}=13)$ & $0 \cdot 8(0.9)$ & $0 \cdot 1(0 \cdot 3)$ & $0.7(0.6)$ \\
Nondepressed Parkinsonians $(\mathrm{n}=11)$ & $2 \cdot 9(0 \cdot 8)$ & $0 \cdot 2(0 \cdot 5)$ & $2 \cdot 7(0.7) \ddagger$ \\
Patients with major depression $(\mathrm{n}=14)$ & $1 \cdot 6(1 \cdot 5)$ & $0 \cdot 4(0 \cdot 5)$ & $1 \cdot 2(0 \cdot 9) \dagger$ \\
Controls $(\mathrm{n}=12)$ & $3 \cdot 1(1.0)$ & $0 \cdot 4(0.6)$ & $2 \cdot 7(0 \cdot 9) \ddagger$ \\
\hline
\end{tabular}

tp $<0.05$ on the Wilcoxon Signed Rank test.

tp $<\mathbf{0 . 0 1}$ on the Wilcoxon Signed Rank ttest.

*The score was attributed according to the method of Wald et al (1978) (see text). 
appreciated by means of purposely-developed and formally validated self-rating scales. ${ }^{1721}$ Owing to euphoria, the vast majority of the subjects are immediately able to distinguish intravenous central stimulants from placebos ${ }^{36}$ hence the potentiality for abuse, which has been recognised also for methylphenidate $^{37}$ and is an obvious proof of its rewarding effect.

Our controlled methylphenidate trials showed that the group of Parkinsonian patients with major depression was significantly less able to distinguish the active drug from placebo than nondepressed Parkinsonians, than nonparkinsonians suffering from major depression and than controls without CNS or psychiatric disease. At variance with the other three groups, in Parkinsonian patients with major depression MTP substantially failed to produce any average mood change towards a euthymic or a euphoric state. This lack of response emerged not only from the selfratings, but also from the "blind" observers's ratings and from the percentage of "positive responders". Different mood response to MTP in the two Parkinsonian groups could not be ascribed to any difference in the baseline disability or in the motor response, since these were quite similar. Moreover, the more depressed Parkinsonian patients, the poorer was their mood response to the active drug, a correlation that was not found among nonparkinsonian depressed patients. Mood response to methylphenidate in our "normal" control group closely resembled that found by previous authors. ${ }^{21}$ The percentage of non-parkinsonian subjects with major depression who showed significantly mood amelioration on methylphenidate is also similar to that found by previous investigators. ${ }^{20}$ For a standard dose of $20-30 \mathrm{mg}$, about one in two of these patients will exhibit a positive mood swing. None of the variables measured in this group correlated significantly with response quality. The significant difference in the response observed between depressed patients with and without Parkinson's disease suggests that the pathophysiological processes underlying mood changes may somehow be different in the two groups. Indeed, this view is supported by the much higher percentage of "anhedonic" patients in the depressed Parkinsonian group, as evaluated by the method of Fawcett et al..$^{31}$ To our surprise, nondepressed Parkinsonians were the group that showed the highest ratio of positive responsers to methylphennidate injections. When a comparison with controls was made, however, the difference did not reach statistical significance.

Previous studies with central stimulants in endogenous depression paid little attention to possible pathophysiological implications resulting from the drug mechanism of action..$^{2038}$ The neuropsychic effects of stimulants are commonly explained in terms of their action on all three monoamingeric systems in the brain. ${ }^{32}$ However, it has been repeatedly demonstrated that the ability of these compounds to produce euphoria or pleasure is a specific dopamine-dependent function in humans, since it is selectively abolished by dopamine receptor blockers. ${ }^{18}$ Animal data indicate the ventral tegmental area in the mesenkephalon (VTA), a dopamine-neuron containing region, as the structure whose integrity is necessary for the production of the reward reaction in self-stimulation experiments. ${ }^{39}$ Dopamine projections from this area to the nucleus accumbens are of crucial importance to the reward effect produced by the intravenous self-administration of amphetamines. ${ }^{40}$ Dopaminergic fibres that arise from the VTA have a wide distribution in the mammalian telenkephalon ${ }^{41}$ : one group reaches the prefrontal cortex, while others are directed to the ventral striatum (where the nucleus accumbens is situated), the piriform and the entorhinal cortex, the olfactory bulb, and the amygdaloid and the septal nueclei. Positron emission tomography studies of patients with depression have associated a euthymic response to methylphenidate with changes in the metabolism of a wide cortical area in the frontal and temporal lobe. ${ }^{38}$ Thus, we have no direct information about which subgroup of mesocorticolimbic dopamine fibres might mediate the euphoric response to sympathomimetics in man. The fact remains that the ventral tegmental area is the region where a dopaminergic projection arises, which possesses specific reward- or pleasure-related functions, and is sensitive to central stimulants. Cell-count investigation have shown that this nucleus is affected-to a variable degree-in Parkinson's disease, ${ }^{42}$ a finding that confirmed earlier biochemical evidence. ${ }^{43}$ The inability to experience reward or pleasure ("anhedonia") is thought to be a marker for a subgroup of "organically-based" depression states. ${ }^{44}$ Accordingly, we confined our study to patients with rather severe and persisting depression, in the belief they were more appropriate for investigation of a biologically-based illness than those with obvious reactive or transient adverse mood changes.

CNS effects of central stimulants are diminished or abolished if monoamine stores are depleted. ${ }^{32}$ Thus, the evident lack of euphoric response to methylphenidate seems to confirm the postulated derangement of the reward-related dopamine synapse in our Parkinsonian patients with major depression. This view is further supported by the anhedonic nature of their depressive symptoms. Subjects with a low "hedonic capacity" are less able to buffer affectively painful events with pleasurable activities, and thus become more vulnerable to depression. ${ }^{45}$ This model seems plausible for our patients, faced with the chronic disability of Parkinson's disease. We interpret our data as an evidence for the view that, in a subgroup of 
severely depressed Parkinsonians, biological factors, namely derangement of the hedonic dopamine circuitry, may interact with reactive ones in the pathogenesis of depression. Obviously, this conclusion is not to be extended to all subtypes ${ }^{9}$ of Parkinsonian depression. Moreover, given the complexity of the human "rewarding" system, ${ }^{19}$ the possible contribution of other transmitters and/or modulators must be taken into account.

The motor effects of methylphenidate also deserve comment. In their pilot study, Halliday and Nathan ${ }^{33}$ reported that rigidity and akinesia, but not tremor, were very often relieved by the intravenous injection of the drug, which also produced marked euphoria in half of their subjects. Not only did we confirm these findings, but we were also much impressed by the fact that methylphenidate produced a motor change virtually identical to "kinesia paradoxica" in two of our depressed Parkinsonian patients, whose motor performance on acute methylphenidate was much better than on adjusted levodopa doses. Moreover, the latter were never associated with a euphoric mood change as pronounced as that induced by methylphenidate. Rapid reversal of akinesia in these two subjects given methylphenidate was invariably preceded and accompanied by a striking upward mood swing, as if the sudden restoration of mechanisms implicated in movement initiation were strictly conditioned by a euphoric change of the affective state. Wise ${ }^{19}$ suggested that the hedonic dopamine synapse stimulated by central sympathomimetics may play a critical role in motivational processes. Iversen and Fray ${ }^{46}$ have reported that experimental damage to the ventral tegmental area was found to impair organised motivational behaviour in the rat. Limbic and frontal structures that receive dopaminergic input from the VTA have many important connections with and within the ventromedial striatum. ${ }^{47}$ On the whole, the latter is believed to function as an interface between the motivational and the more strictly motor aspects of movement, since, for instance, it is activated by "stimuli associated with reward or punishment" in primates.$^{48}$ One of its main components is the nucleus accumbens, which has been implicated in movement initiation $^{49}$ and receives a direct dopaminergic projection from the ventral tegmental area. At the same time, the site of the nucleus accumbens is exactly where the stimulant-sensitive dopamine synapse has been located.$^{40}$ Caution must be used in transferring these animal data to the human striatum..$^{50}$ Besides, our suggestion that accumbens dopamine levels may be relevant to the motivation/movement link in Parkinson's disease is somehow in parallel with the findings of Gotham et al..$^{\text {s1 }}$ These authors proposed that some specific cognitive deficits in Parkinson's disease may be related to selective caudate dopamine dysfunction.
Hence, the concept arises that different Parkinsonian symptoms may be explained in terms of different degrees of dopamine loss or dysfunction in different terminal regions. At least, our unexpected finding suggests that, in future studies of kinesia paradoxica pathophysiology, more attention should be paid to the $\mathrm{n}$. accumbens, as a fascinating putative site of interaction between emotion and motion.

\section{References}

1 Gotham AM, Brown RG, Marsden CD. Depression and Parkinson's disease: a quantitative and qualitative analysis. $J$ Neurol Neurosurg Psychiatry 1986;49:381-9.

2 Warburton JW. Depressive symptoms in Parkinson patients referred for thalamotomy. J Neurol Neurosurg Psychiatry 1967;30:368-70.

3 Marsh GG, Markham CG. Does levodopa alter depression and psychopathology in Parkinsonism patients? J Neurol Neurosurg Psychiatry 1973;36:925-35.

4 Robins AH. Depression in patients with parkinsonism. Br J Psychiatry 1976;128:141-5.

5 Cantello R, Gilli M, Riccio A, Bergamasco B. Mood changes associated with "end-of-dose deterioration" in Parkinson's disease: a controlled study. J Neurol Neurosurg Psychiatry 1986;49:1182-90.

6 Horn S. Some psychological factors in parkinsonism. $J$ Neurol Neurosurg Psychiatry 1974;37:27-31.

7 Celesia GC, Wanamaker WM. Psychiatric disturbances in Parkinson's disease. Dis Nerv Syst 1972;33:577-83.

8 Mayeux R, Stern T, Cote L, Leventhal J. Depression, intellectualo impairment and Parkinson's disease. Neurology 1981;31 645-50.

9 Mayeux R, Williams JBW, Stern J, Cote' L. Depression and Parkinson's disease. In: Hassler RG, Christ JF, eds. Parkinson specific motor and Mental Disorders. Role of the Pallidum: Pathophysiological, Biochemical and Therapeutic aspects. Advances in Neurology, vol 40. New York: Raven Press, 1984:241-50.

10 Santamaria J, Tolosa E, Valles A. Parkinson's disease with depression: a possible subgroup of idiopathic parkinsonism Neurology 1986;36:1130-3.

11 Taylor AE, Saint-Cyr JA, Lang AE, Kenny FT. Parkinson's disease and depression: a critical re-evaluation. Brain 1986;109:279-92.

12 Javoy-Agid F, Ruberg M, Taquet H. Biochemical neuropathology of Parkinson's disease. In: Hassler RG, Christ JF, eds. Parkinson-specific Motor and Mental Disorders. Role of the Pallidum: Pathophysiological, Biochemical and Therapeutic aspects. Advances in Neurology, vol 40. New York: Raven Press, 1984:189-98.

13 Van Praag HM. Depression. Lancet 1982;ii:1259-64.

14 Mayeux R, Stern Y, Cote L, Williams JBW. Altered serotonin metabolism in depressed patients with Parkinson's disease. Neurology 1984;34:642-6.

15 Kostic VS, Djuricic BM, Covickovic-Sternic N, Bumbasirevic L, Nickolic M, Mrsulja BB. Depression and Parkinson's disease: possible role of serotonergic mechanisms. $J$ Neurol 1987;234:94-6.

16 Fibiger HC. The neurobiological substrates of depression in Parkinson's disease: a hypothesis. Can J Neurol Sci 1984;11:105-7.

17 Van Kammen DP, Murphy DL. Attenuation of the euphoriant and activating effects of $\mathrm{d}$ - and 1-amphetamine by lithium carbonate treatment. Psychopharmacologia 1975;44:215-24.

18 Wald D, Ebstein RP, Belmaker RH. Haloperidol and lithium 
blocking of the mood response to methylphenidate. Psychopharmacology 1978;57:83-7.

19 Wise RA. The dopamine synapse and the notion of "pleasure centers" in the brain. TINS 1980;4:91-5.

20 Brown P, Brawley P. Dexamethasone suppression test and mood response to methylphenidate in primary depression. Am J Psychiatry 1983;140:990-3.

21 Martin WR, Sloan JW, Sapira JD, Jasinski DR. Physiologic, subjective, and behavioural effects of amphetamine, metamphetamine, ephedrine, phenmetrazine, and methylphenidate in man. Clin Pharmacol Ther 1971;12:245-58.

22 Hachinksi VC, Linnette DI, Zilhka E, et al. Cerebral blood flow in dementia. Arch Neurol 1975;32:632-7.

23 Folstein M, Folstein S, McHugh PJ. "Mini-mental state": a practical method for grading the cognitive state of patients for the clinician. J Physchiat Res 1975;12:189-98.

24 Duvoisin RC. The evaluation of extrapyrimidal disease. In: de Ajuriaguerra J, Gauthier G, eds. Monoamines, Noyaux Gris Centraux et Syndrome de Parkinson. Paris: Masson, 1971: 313-25.

25 Marsden CD. Basal Ganglia Disease. Lancet 1982;ii:1141-6.

26 American Psychiatric Association. Diagnostic and statistical manual of mental disorders. Washington, DC 1980:205-24.

27 Beck AT, Ward CH, Mendelson M, Mock J, Erbaugh J. An inventory for measuring depression. Arch Gen Psychiat 1961;4:53-63.

28 Stern J, Mayeux R, Rosen J. Contribution of perceptual motor dysfunction to construction and tracing disturbances in Parkinson's disease. J Neurol Neurosurg Psychiatry 1984;47:983-9.

29 Direnfeld LK, Albert ML, Vollicer L, Langlais PJ, Marquis J, Kaplan E. Parkinson's disease. The possible relationship of laterality to dementia and neurochemical findings. Arch Neurol 1984;41:935-41.

30 Cantello R, Riccio A, Scarzella L, Leotta D, Bergamasco B. Depression in Parkinson disease: a disabling but neglected factor. Ital J Neurol Sci 1984;5:417-22.

31 Fawcett J, Clark DC, Scheftner WA, Gibbons RD. Assessing anhedonia in psychiatric patients. The pleasure scale. Arch Gen Psychiat 1983;40:79-84.

32 Kuczenski R. Biochemical actions of amphetamines and other stimulants. In: Creese I, ed. Stimulants: Neurochemical, Behavioural and Clinical Perspectives. New York: Raven Press, 1983:31-61.

33 Halliday AM, Nathan PW. Methylphenidate in Parkinsonism. Br Med J 1961;1:1652-5.

34 Cantello R, Aguggia M, Gilli M, Delsedime M, Riccio A, Rainero I, Mutani R. Analgesic action of methylphenidate on parkinsonian sensory symptoms: mechanisms and pathophysiological implications Arch Neurol 1988;45:973-6.

35 Marsden CD, Parkes JD. "On-off" effects in patients with Parkinson's disease on chronic levodopa therapy. Lancet 1976;i:292-6.

36 Jonsson LE, Anggard E, Gunne LE. Blockade of intravenous amphetamine euphoria in man. Clin Pharm Ther 1971;12:88996.

37 McCormick TC, Jr, McNeil TW. Acute psychosis and Ritalin abuse. Texas State J Med 1962;59:99-100.

38 Phelps ME, Mazziotta JC, Baxter L, Gerner R. Positron emission tomographic study of affective disorders: problems and strategies. Ann Neurol 1984;15(suppl):S149-S156.

39 Phillips AG, Fibiger HC. The role of dopamine in maintaining intracranial self-stimulation in the ventral tegmentum, nucleus accumbens, and prefrontal cortex. Can J Psychol 1978;32: 58-66.

40 Lyness WH, Friedle NM, Moore KE. Destruction of dopaminergic terminals in nucleus accumbens: effect on d-amphetamine self-administration. Pharm Biochem Behav 1979;11:553-6.

41 Glowinski J, Tassin JP, Thierry AM. The mesocortico-prefrontal dopaminergic neurons. TINS 1984;7:415-8.

42 Uhl GR, Hedreen JC, Price DL. Parkinson's disease: loss of neurons from the ventral tegmental area contralateral to therapeutic surgical lesions. Neurology 1985;35:1215-8.

43 Javoy-Agid F, Agid Y. Is the mesocortical dopaminergic system involved in Parkinson's disease? Neurology 1980;30:1326-30.

44 Klein D. Endogenomorphic depression: a conceptual and terminological revision. Arch Gen Psychiat 1974;31:447-54.

45 Meehl P. Hedonic capacity: some conjectures. Bull Menninger Clin 1975;39:295-307.

46 Iversen SD, Fray PJ. Brain cathecolamines in relation to affect. In: Beckman A, ed. The Neural Basis of Behavior. New York: Spectrum Press, 1982:229-69.

47 Nauta WJA, Domesick VB. Afferent and efferent relationships of the basal ganglia. In: Evered D, O'Connor M, eds. Functions of the Basal Ganglia. London: Pitman, 1984:3-29.

48 Rolls ET. Responses of neurons in different regions of the striatum of the behaving monkey. In: McKenzie J, Wilcox L, eds. The Basal Ganglia: Structure and Function. New York: Plenum Press, 1984:93-113.

49 De Long MR, Georgopoulos AP. Motor functions of the basal ganglia. In: Brooks VB, ed. Handbook of Physiology: the Nervous System, vol 2. Bethesda, MD: American Physiological Society, 1981:1017-61.

50 Rothwell JC. Control of Human Voluntary Movement. London: Croom Helm, 1987.

51 Gotham AM, Brown RG, Marsden CD. "Frontal" cognitive function in patients with Parkinson's disease "on" and "off" levodopa. Brain 1988;111:299-321.

\section{Appendix}

Items of the self-rating scale which was used to measure methylphenidate responses over a $0-5$ point range.

Activation

feel active

feel alert

feel excited

feel talkative

have racing thoughts

have sexual thoughts

Depressed affect

feel depressed

have difficulty concentrating

have difficulty remembering

feel guilty

feel sad and pessimistic

feel tearful

\section{Somatic symptoms}

have blurred vision

feel cold

feel dizzy

have dry mouth

have a headache

feel hungry

feel nauseated

am perspiring

am thirsty

feel sleepy

feel drowsy

\section{Euphoria}

feel close to people

feel confident

feel euphoric

feel good overall

\section{Dysphoria}

feel anxious

feel angry

feel irritable

feel less in touch with people

feel restless

feel strange

have unusual thoughts 